\title{
Associations between television viewing and consumption of commonly advertised foods among New Zealand children and young adolescents
}

\author{
Jennifer Utter*, Robert Scragg and David Schaaf \\ Epidemiology and Biostatistics, School of Population Health, University of Auckland, Private Bag 92019, \\ Auckland, New Zealand
}

Submitted 22 March 2005: Accepted 8 November 2005

\begin{abstract}
Objectives: To explore how time spent watching television (TV) is associated with the dietary behaviours of New Zealand children and young adolescents.

Design: Secondary data analysis of a nationally representative, cross-sectional survey. Setting: In homes or schools of New Zealand school students.

Participants: In total, 3275 children aged 5 to 14 years.

Results: The odds of being overweight or obese increased with duration of TV viewing for children and adolescents when controlling for age, sex, ethnicity, socio-economic status and physical activity. Children and adolescents who watched the most TV were significantly more likely to be higher consumers of foods most commonly advertised on TV: soft drinks and fruit drinks, some sweets and snacks, and some fast foods. Both children and adolescents watching two or more hours of TV a day were more than twice as likely to drink soft drinks five times a week or more $(P=0.03$ and $P=0.04$, respectively), eat hamburgers at least once a week (both $P=0.02$ ), and eat French fries at least once a week (both $P<0.01$ ).

Conclusions: These findings suggest that longer duration of TV watching (thus, more frequent exposure to advertising) influences the frequency of consumption of soft drinks, some sweets and snacks, and some fast foods among children and young adolescents. Efforts to curtail the amount of time children spend watching TV may result in better dietary habits and weight control for children and adolescents. Future studies examining the impact of advertising on children's diets through interventions and international comparisons of legislation would provide more definitive evidence of the role of advertising in child and adolescent obesity.
\end{abstract}

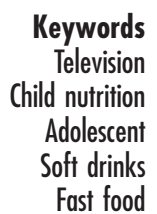

Keywords

Child nutrition

Soft drinks

Fast food
More than one-quarter of television (TV) advertisements aired during the early evening in New Zealand promote food or food retailers ${ }^{1,2}$. Nearly $30 \%$ of food advertisements New Zealand children are exposed to annually are for sweet snacks, nearly 20\% for drinks (particularly carbonated drinks), and 15\% are for fast-food restaurants. Numerous studies have demonstrated that these foods, especially soft drinks and fast food, are important in the aetiology and prevention of childhood obesity ${ }^{3}$. In contrast, only $5 \%$ of food advertisements are for fruit (including pure fruit juice) and fewer than 5\% are for dairy products $^{1}$. Food companies and retailers invest heavily in TV advertising as a marketing strategy. During 2003, McDonald's System of New Zealand spent more than \$NZ 19 million on TV advertising and Coca-Cola New Zealand and Cadbury Confectionery each spent more than \$NZ 15 million ${ }^{4}$. These companies far outspend some of New Zealand's best social marketing efforts. For example, the Push Play campaign, which encouraged New Zealanders to increase their physical activity, had a budget of a mere \$NZ 3 million for its entire media campaign from 1999 to $2002^{5}$.

The types of foods advertised in New Zealand are similar to those in many other industrialised countries. Content analyses of advertisements on children's TV in Australia ${ }^{6}$, the $\mathrm{UK}^{7}$ and the $\mathrm{USA}^{8}$ have all demonstrated that the foods most commonly advertised are high in fat/ sugar. In Australia, it was estimated that if a child watched the average 2.5 hours of TV per day, they would be exposed to 77 advertisements per week for high-fat/highsugar foods ${ }^{6}$.

The positive relationship between TV viewing and obesity has been well documented internationally ${ }^{9-14}$, but the process by which TV viewing contributes to weight gain is less understood. Possible explanations include increased snacking while watching TV, increased time spent being inactive, and increased overall consumption due to exposure to food advertising. The impact of food advertising is of particular interest since regulating food advertising on TV can have widespread impact on the 
majority of the population. In contrast, modifying eating and activity patterns in children's homes to decrease snacking during TV and encouraging children to be more active can be difficult. While parents and families play an important role in their children's food choices, the pervasiveness and intensity of food advertising to children make it difficult for parents to shield their children from these influences ${ }^{15}$.

The current study aimed to examine how TV viewing (and, thus, frequency of exposure to advertisements) is associated with the food consumption pattern of New Zealand children. The objectives of the study were to: describe the demographic characteristics of children and young adolescents by duration of TV use; examine the association between TV use and weight status; and examine how duration of TV viewing is associated with the frequency of consumption of the most frequently advertised foods on TV.

\section{Methods}

\section{Study population and study design}

The current paper reports data collected in the 2002 National Children's Nutrition Survey (CNSO2). The full report and methods have been published elsewhere ${ }^{16}$ and are also available online (www.moh.govt.nz). CNSO2 was a cross-sectional population survey that assessed multiple indicators of child nutrition through interviews, dietary assessments, anthropometric measurements and clinical measures. Data for the current study were collected as part of the Food Habits and Physical Activity Interviews and the Food-Frequency Questionnaire (FFQ). The interviews and the FFQ were administered at students' homes; parents helped to complete the interviews and FFQ if the child was under the age of 10 years or unable to complete them alone. Written consent was received from all parents of participating students. All regional health ethics committees in New Zealand granted ethical approval for the study.

CNSO2 used a two-stage cluster sample design to produce a representative sample of New Zealand school children, aged 5 to 14 years. Maori and Pacific students were oversampled to ensure approximately equal numbers of children in each ethnic group in the final survey sample. The first stage involved random sampling of schools with children aged 5-14 years, and the second stage involved random sampling of students within schools. The final study sample comprised 3275 students (student response 69.3\%).

\section{Measures}

Time spent watching TV or videos was measured by a series of branching questions that asked about duration of viewing over the previous week. For example, students were asked 'Did you watch TV or videos last Sunday?' If they responded 'yes', they were then asked how many hours they watched TV or videos. An hours-per-day variable was created by averaging total TV use. The hoursper-day variable was then categorised at the nearest whole hour to the 33rd and 66th percentiles for the distribution of daily TV use. The resulting categories were ' $<1$ h', ' 1 to $<2$ h' and ' $\geq 2$ h'.

In 1999, two separate studies were published documenting the types of foods advertised on TV in New Zealand during the hours that children and adolescents were most likely to be watching ${ }^{1,2}$. These studies were conducted prior to data collection for $\mathrm{CNSO2}$, but they contain the most recent and relevant information for New Zealand. In general, the most commonly advertised foods in New Zealand were snack foods and sweet snacks, drinks and fast foods, and the least commonly advertised foods were fruits, vegetables and milk. These findings guided the selection of food items for analysis in the current study. The foods selected included: potato crisps, chocolate sweets, biscuits, carbonated soft drinks, fruit drinks (not 100\% juice), hamburgers, fried chicken and French fries, fruit (average consumption of 10 fruits), vegetables (average consumption of 17 vegetables, excluding potatoes, taro, and kumara or sweet potato) and non-flavoured milk. Because the responses for each food item's consumption were not normally distributed, each of the food variables was dichotomised to create a high consumption category and a low or average consumption category, with cut-points made at the 75th percentiles for each food item. The FFQ developed for CNSO2 has similar or better repeatability among New Zealand children of all major ethnic groups compared with other child or adolescent FFQs ${ }^{17}$.

Weight status was based on height and weight measurements taken by trained research staff using standardised equipment and procedures. Body mass index (BMI) was calculated as weight (kilograms) divided by the square of height (metres). Overweight and obesity were defined using international BMI cut-points for children $^{18}$.

Physical activity was assessed using a modified version of the previously validated Physical Activity Questionnaire for Children (PAQ-C) ${ }^{19,20}$. Age, sex and ethnicity (classified as Maori, Pacific or New Zealand European/ Other, NZEO) were each determined by parent and/or adolescent self-report. The proxy measure used for socioeconomic status (SES) was the New Zealand Deprivation Index (NZDep) ${ }^{21}$. Created from the 1996 Census of Population and Dwellings, NZDep describes the deprivation experienced by groups of people living in private accommodation in a small area.

\section{Analysis}

All analyses were conducted separately for two age groups, children (ages 5 to 10 years) and adolescents (ages 11 to 14 years), because of the developmental differences between children and adolescents. Age is likely to moderate the findings by influencing the programming 
choices and timing of TV use, and because young adolescents are likely to have more independence in food purchases and choices than younger children. The statistical software SUDAAN (version 9.0; Research Triangle Institute, Research Triangle, NC, USA) was used to correct design effects from clustered sampling, with weighting to the New Zealand population of children aged 5 to 14 years. The demographic data of students' TV habits were generated by cross-tabulations using chi-square tests to determine statistical differences. Generalised log linear models were used to compare the odds of overweight, obese and normal weight by category of TV use while controlling for age, sex, ethnicity, SES and physical activity. Logistic regression was used to generate the odds ratios for consumption of the selected food items by category of TV use, adjusting for age, sex, ethnicity and SES.

\section{Results}

The demographic characteristics of students by TV viewing habits are described in Table 1. Nearly 30\% of children and nearly $40 \%$ of adolescents watched TV for two or more hours per day. For both children and

Table 1 Frequency of daily television (TV) watching by demographic characteristics of students

\begin{tabular}{|c|c|c|c|c|c|}
\hline & \multirow[b]{2}{*}{$n$} & \multicolumn{3}{|c|}{$\begin{array}{c}\text { Daily TV watching } \\
(\%)\end{array}$} & \multirow[b]{2}{*}{$P$-value } \\
\hline & & $<1 \mathrm{~h}$ & 1 to $<2 \mathrm{~h}$ & $\geq 2 \mathrm{~h}$ & \\
\hline \multicolumn{6}{|l|}{ Children, $5-10$ years } \\
\hline Total & 1878 & $31.2^{*}$ & 41.0 & 27.8 & \\
\hline Males & 994 & 31.0 & 40.9 & 28.1 & \\
\hline Females & 884 & 31.4 & 41.0 & 27.6 & 0.99 \\
\hline \multicolumn{6}{|l|}{ Ethnicity } \\
\hline Maori & 754 & 21.7 & 40.0 & 38.3 & \\
\hline Pacific & 604 & 30.8 & 36.4 & 32.8 & \\
\hline NZEO & 520 & 34.5 & 41.8 & 23.7 & 0.001 \\
\hline \multicolumn{6}{|l|}{ NZDep quintile† } \\
\hline 1 (least deprived) & 186 & 42.0 & 41.7 & 16.3 & \\
\hline 2 & 220 & 39.2 & 42.4 & 18.4 & \\
\hline 3 & 235 & 23.9 & 41.7 & 34.4 & \\
\hline 4 & 364 & 25.8 & 41.8 & 32.4 & \\
\hline 5 (most deprived) & 873 & 25.3 & 37.9 & 36.8 & 0.001 \\
\hline \multicolumn{6}{|c|}{ Adolescents, $11-14$ years } \\
\hline Total & 1026 & $26.8^{*}$ & 35.8 & 37.4 & \\
\hline Males & 510 & 26.3 & 37.7 & 36.0 & \\
\hline Females & 516 & 27.4 & 33.7 & 38.9 & 0.62 \\
\hline \multicolumn{6}{|l|}{ Ethnicity } \\
\hline Maori & 302 & 19.6 & 31.5 & 48.9 & \\
\hline Pacific & 395 & 31.6 & 30.5 & 38.0 & \\
\hline NZEO & 329 & 28.5 & 37.7 & 33.8 & 0.023 \\
\hline \multicolumn{6}{|l|}{ NZDep quintile† } \\
\hline 1 (least deprived) & 109 & 31.0 & 35.5 & 33.5 & \\
\hline 2 & 140 & 28.4 & 33.0 & 38.5 & \\
\hline 3 & 149 & 28.8 & 40.7 & 30.5 & \\
\hline 4 & 174 & 21.4 & 38.0 & 40.6 & \\
\hline 5 (most deprived) & 454 & 23.9 & 32.6 & 43.5 & 0.53 \\
\hline
\end{tabular}

NZEO - New Zealand European/Other;

${ }^{*}$ Weighted percentages; row percentages add to $100 \%$.

†New Zealand Index of Deprivation score. adolescents, there were no significant differences in TV viewing by gender, but there were significant differences by ethnicity. Among children, Maori and Pacific students were more likely to watch TV for two or more hours per day than NZEO children. Similarly, nearly 50\% of Maori adolescents watched TV for two or more hours per day, compared with 38\% of Pacific and 34\% of NZEO adolescents $(P<0.05)$. TV watching was strongly correlated with SES among children, but not adolescents.

The relationship between duration of TV viewing and weight status is described in Table 2. Time spent watching TV was an independent correlate of obesity, when controlling for age, sex, ethnicity, SES and physical activity, among children (odds ratio (OR) 2.1; 95\% confidence interval (CI) 1.1-4.0) and adolescents (OR 2.9; 95\% CI 1.55.7). The associations between TV viewing and overweight were not significant for children or adolescents.

The associations between TV viewing and frequency of consumption of the most advertised and least advertised foods are described in Table 3 for children and Table 4 for adolescents. Children who watched two or more hours of TV per day were less likely to be high consumers of fruits and vegetables; the relationship with milk consumption was not statistically significant. Children who watched two or more hours of TV per day were more likely to be high consumers of all of the commonly advertised foods, except for chocolate sweets and fried chicken. Specifically, children watching two or more hours of TV per day were more than twice as likely to be high consumers of soft drinks $(P=0.029)$, hamburgers $(P=0.016)$ and French fries $(P<0.001)$ than children watching less than an hour of TV daily.

Among adolescents, fewer but more significant associations were seen between TV viewing and consumption of commonly advertised foods. Adolescents who watched one or more hours of TV per day were more than twice as likely to be high consumers of soft drinks $(P=0.036)$ and chocolate sweets $(P=0.004)$ than adolescents watching TV for less than an hour. Similarly, the odds for being high consumers of hamburgers or French fries increased with time spent watching TV. No relationships were statistically significant between TV use and consumption of fruits and vegetables, milk, fruit drinks, potato chips, biscuits or fried chicken among adolescents, who had a smaller sample size than children.

Analyses of the total sample (5-14 years) showed that TV use was positively associated with the consumption of soft drinks, fruit drinks, potato crisps, chocolate sweets, biscuits, hamburgers and French fries (not fried chicken), and negatively associated with the consumption of fruits and vegetables (data not shown).

\section{Discussion}

Nearly $30 \%$ of children and nearly $40 \%$ of adolescents spend two or more hours a day watching TV. Watching two 
Table 2 Odds ratios (OR) and 95\% confidence intervals $(\mathrm{Cl})$ of being overweight or obese (compared with normal weight) by level of television (TV) viewing, controlling for age, sex, ethnicity, socio-economic status and physical activity

\begin{tabular}{|c|c|c|c|c|c|c|}
\hline & \multirow[b]{2}{*}{$n$} & \multicolumn{2}{|c|}{ Overweight } & \multicolumn{2}{|c|}{ Obese } & \multirow[b]{2}{*}{$P$-value $\dagger$} \\
\hline & & $\%{ }^{*}$ & OR $(95 \% \mathrm{Cl})$ & $\%^{*}$ & OR $(95 \% \mathrm{Cl})$ & \\
\hline \multicolumn{7}{|c|}{ Children, $5-10$ years } \\
\hline \multicolumn{7}{|c|}{ Daily TV watching } \\
\hline$<1 \mathrm{~h}$ & 504 & 17.3 & 1.0 & 5.2 & 1.0 & \\
\hline 1 to $<2 \mathrm{~h}$ & 690 & 20.4 & $1.2(0.8-1.9)$ & 8.3 & $1.6(0.9-2.80$ & \\
\hline$\geq 2 \mathrm{~h}$ & 550 & 25.3 & $1.6(1.0-2.6)$ & 12.1 & $2.1(1.1-4.0)$ & 0.15 \\
\hline \multicolumn{7}{|c|}{$\begin{array}{l}\text { Adolescents, } 11-14 \text { years } \\
\text { Daily TV watching }\end{array}$} \\
\hline$<1 \mathrm{~h}$ & 268 & 21.6 & 1.0 & 5.0 & 1.0 & \\
\hline 1 to $<2 \mathrm{~h}$ & 323 & 22.3 & $1.1(0.7-1.8)$ & 9.3 & $2.1(1.1-4.1)$ & \\
\hline$\geq 2 \mathrm{~h}$ & 381 & 21.3 & $1.1(0.7-1.8)$ & 14.0 & $2.9(1.5-5.7)$ & 0.040 \\
\hline
\end{tabular}

* Weighted percentages; unadjusted for effects of age, ethnicity, sex, physical activity and socio-economic status. $\dagger P$-value for Wald- $F$.

or more hours of TV daily was more common among Maori students and children from more economically deprived households. Ethnic differences in duration of TV viewing are likely to be confounded by SES since in New Zealand Maori and Pacific peoples are overrepresented among indicators of socio-economic deprivation ${ }^{22}$. Research from

Table 3 Odds ratios (OR) and 95\% confidence intervals $(\mathrm{Cl})$ for the associations between high consumption of selected foods and frequency of television (TV) watching, controlling for age, sex, ethnicity and socio-economic status: children, aged 5-10 years

\begin{tabular}{|c|c|c|c|c|c|c|c|c|c|c|c|c|}
\hline & \multicolumn{12}{|c|}{ Least advertised } \\
\hline & \multicolumn{4}{|c|}{ Fruit (3+ times per day) } & \multicolumn{4}{|c|}{ Vegetables (4+ times per day) } & \multicolumn{4}{|c|}{ Milk (5+times per week) } \\
\hline & $n$ & $\%^{*}$ & OR $(95 \% \mathrm{Cl})$ & $P$-value & $n$ & $\%$ & OR $(95 \% \mathrm{Cl})$ & $P$-value & $n$ & $\%$ & OR $(95 \% \mathrm{Cl})$ & $P$-value \\
\hline \multicolumn{13}{|c|}{ Daily TV watching } \\
\hline$<1 \mathrm{~h}$ & 511 & 37.0 & 1.0 & & 510 & 29.2 & 1.0 & & 534 & 47.9 & 1.0 & \\
\hline 1 to $<2 h$ & 697 & 29.5 & $0.7(0.5-1.0)$ & & 697 & 28.3 & $0.9(0.6-1.3)$ & & 753 & 45.1 & $0.9(0.6-1.3)$ & \\
\hline$\geq 2 \mathrm{~h}$ & 559 & 20.4 & $0.5(0.3-0.7)$ & 0.003 & 555 & 21.0 & $0.6(0.4-0.9)$ & 0.07 & 591 & 43.5 & $0.9(0.6-1.4)$ & 0.90 \\
\hline & \multicolumn{8}{|c|}{ Beverages } & & & & \\
\hline & \multicolumn{4}{|c|}{ Soft drinks (5+times per week) } & \multicolumn{4}{|c|}{ Fruit drinks ( $1+$ times per day) } & & & & \\
\hline & $n$ & $\%^{*}$ & OR $(95 \% \mathrm{Cl})$ & $P$-value & $n$ & $\%$ & OR $(95 \% \mathrm{Cl})$ & $P$-value & & & & \\
\hline \multirow{7}{*}{$\begin{array}{l}\text { Daily TV wat } \\
\quad<1 \mathrm{~h} \\
1 \text { to }<2 \mathrm{~h} \\
\geq 2 \mathrm{~h}\end{array}$} & & & & & & & & & & & & \\
\hline & 534 & 7.6 & 1.0 & & 534 & 25.2 & 1.0 & & & & & \\
\hline & 753 & 12.7 & $1.7(1.0-2.8)$ & & 753 & 38.9 & $1.9(1.3-2.7)$ & & & & & \\
\hline & 591 & 17.7 & $2.2(1.2-4.0)$ & 0.029 & 591 & 36.6 & $1.7(1.1-2.6)$ & 0.002 & & & & \\
\hline & \multicolumn{12}{|c|}{ Sweets and snacks } \\
\hline & \multicolumn{4}{|c|}{$\begin{array}{c}\text { Potato crisps } \\
\text { (5+times per week) }\end{array}$} & \multicolumn{4}{|c|}{$\begin{array}{l}\text { Chocolate sweets } \\
(3+\text { times per week) }\end{array}$} & \multicolumn{4}{|c|}{$\begin{array}{c}\text { Biscuits } \\
(1+\text { times per day })\end{array}$} \\
\hline & $n$ & $\%{ }^{*}$ & OR $(95 \% \mathrm{Cl})$ & $P$-value & $n$ & $\%$ & OR $(95 \% \mathrm{Cl})$ & $P$-value & $n$ & $\%$ & OR $(95 \% \mathrm{Cl})$ & $P$-value \\
\hline \multirow{7}{*}{$\begin{array}{l}\text { Daily TV wat } \\
\quad<1 \mathrm{~h} \\
1 \text { to }<2 \mathrm{~h} \\
\quad \geq 2 \mathrm{~h}\end{array}$} & & & & & & & & & & & & \\
\hline & 534 & 24.8 & 1.0 & & 534 & 17.0 & 1.0 & & 534 & 21.5 & & \\
\hline & 753 & 35.7 & $1.6(1.1-2.4)$ & & 753 & 20.9 & $1.2(0.8-1.9)$ & & 753 & 35.2 & $2.0(1.3-3.1)$ & \\
\hline & 591 & 39.1 & $1.8(1.3-2.6)$ & 0.003 & 591 & 26.4 & $1.5(1.0-2.3)$ & 0.17 & 591 & 27.4 & $1.5(1.0-2.2)$ & 0.006 \\
\hline & \multicolumn{12}{|c|}{ Fast foods } \\
\hline & \multicolumn{4}{|c|}{ Hamburgers (1+times per week) } & \multicolumn{4}{|c|}{ French fries (1+times per week) } & \multicolumn{4}{|c|}{ Fried chicken (1+times per week) } \\
\hline & $n$ & $\%^{*}$ & OR $(95 \% \mathrm{Cl})$ & $P$-value & $n$ & $\%$ & OR $(95 \% \mathrm{Cl})$ & $P$-value & $n$ & $\%$ & OR $(95 \% \mathrm{Cl})$ & $P$-value \\
\hline \multicolumn{13}{|c|}{ Daily TV watching } \\
\hline$<1 \mathrm{~h}$ & 534 & 12.1 & 1.0 & & 534 & 51.6 & 1.0 & & 534 & 11.8 & 1.0 & \\
\hline 1 to $<2 \mathrm{~h}$ & 753 & 15.0 & $1.2(0.8-1.9)$ & & 753 & 63.3 & $1.6(1.2-2.3)$ & & 753 & 13.1 & $1.1(0.7-1.8)$ & \\
\hline$\geq 2 \mathrm{~h}$ & 591 & 24.1 & $2.0(1.2-3.2)$ & 0.016 & 591 & 68.5 & $2.1(1.4-3.1)$ & $<0.001$ & 591 & 21.6 & $1.8(1.1-2.9)$ & 0.07 \\
\hline
\end{tabular}

*Weighted percentages; unadjusted for effects of age, ethnicity, sex, and socio-economic status. 
Table 4 Odds ratios (OR) and 95\% confidence intervals $(\mathrm{Cl})$ for the associations between high consumption of selected foods and frequency of (TV) television watching, controlling for age, sex, ethnicity and socio-economic status: adolescents, aged 11-14 years

\begin{tabular}{|c|c|c|c|c|c|c|c|c|c|c|c|c|}
\hline & \multicolumn{12}{|c|}{ Least advertised } \\
\hline & \multicolumn{4}{|c|}{ Fruit (3+times per day) } & \multicolumn{4}{|c|}{ Vegetables (4+ times per day) } & \multicolumn{4}{|c|}{ Milk (5+times per week) } \\
\hline & $n$ & $\%^{*}$ & OR $(95 \% \mathrm{Cl})$ & $P$-value & $n$ & $\%$ & OR $(95 \% \mathrm{Cl})$ & $P$-value & $n$ & $\%$ & OR $(95 \% \mathrm{Cl})$ & $P$-value \\
\hline \multicolumn{13}{|c|}{ Daily TV watching } \\
\hline$<1 \mathrm{~h}$ & 270 & 27.7 & 1.0 & & 273 & 35.5 & 1.0 & & 282 & 49.2 & 1.0 & \\
\hline 1 to $<2 h$ & 317 & 26.0 & $0.9(0.6-1.5)$ & & 321 & 33.1 & $0.9(0.5-1.6)$ & & 342 & 44.4 & $0.8(0.6-1.2)$ & \\
\hline \multirow[t]{4}{*}{$\geq 2 \mathrm{~h}$} & 375 & 21.1 & $0.7(0.5-1.2)$ & 0.43 & 378 & 27.0 & $0.6(0.4-1.1)$ & 0.12 & 402 & 40.2 & $0.7(0.4-1.1)$ & 0.29 \\
\hline & \multicolumn{8}{|c|}{ Beverages } & & & & \\
\hline & \multicolumn{4}{|c|}{ Soft drinks (5+times per week) } & \multicolumn{4}{|c|}{ Fruit drinks ( $1+$ times per day) } & & & & \\
\hline & $n$ & $\%^{*}$ & OR $(95 \% \mathrm{Cl})$ & $P$-value & $n$ & $\%$ & OR $(95 \% \mathrm{Cl})$ & $P$-value & & & & \\
\hline \multirow{7}{*}{$\begin{array}{c}\text { Daily TV wat } \\
<1 \mathrm{~h} \\
1 \text { to }<2 \mathrm{~h} \\
\geq 2 \mathrm{~h}\end{array}$} & & & & & & & & & & & & \\
\hline & 282 & 11.1 & 1.0 & & 282 & 20.0 & 1.0 & & & & & \\
\hline & 342 & 21.0 & $2.4(1.2-4.6)$ & & 342 & 30.2 & $1.7(0.8-3.5)$ & & & & & \\
\hline & 402 & 23.6 & $2.3(1.2-4.4)$ & 0.036 & 402 & 31.6 & $1.8(1.0-3.4)$ & 0.17 & & & & \\
\hline & \multicolumn{12}{|c|}{ Sweets and snacks } \\
\hline & \multicolumn{4}{|c|}{$\begin{array}{c}\text { Potato crisps } \\
\text { (5+times per week) }\end{array}$} & \multicolumn{4}{|c|}{$\begin{array}{l}\text { Chocolate sweets } \\
(3+\text { times per week })\end{array}$} & \multicolumn{4}{|c|}{$\begin{array}{c}\text { Biscuits } \\
(1+\text { times per day })\end{array}$} \\
\hline & $n$ & $\%^{*}$ & OR $(95 \% \mathrm{Cl})$ & $P$-value & $n$ & $\%$ & OR $(95 \% \mathrm{Cl})$ & $P$-value & $n$ & $\%$ & OR $(95 \% \mathrm{Cl})$ & $P$-value \\
\hline \multirow{7}{*}{$\begin{array}{c}\text { Daily TV wat } \\
<1 \mathrm{~h} \\
1 \text { to }<2 \mathrm{~h} \\
\geq 2 \mathrm{~h}\end{array}$} & & & & & & & & & & & & \\
\hline & 282 & 22.7 & 1.0 & & 282 & 16.9 & 1.0 & & 282 & 21.9 & & \\
\hline & 342 & 33.1 & $1.7(1.0-2.9)$ & & 342 & 30.2 & $2.3(1.3-4.2)$ & & 342 & 31.2 & $1.7(0.9-3.1)$ & \\
\hline & 402 & 35.1 & $1.8(1.0-3.2)$ & 0.14 & 402 & 32.2 & $2.2(1.3-3.6)$ & 0.004 & 402 & 31.8 & $1.7(0.9-3.2)$ & 0.23 \\
\hline & \multicolumn{12}{|c|}{ Fast foods } \\
\hline & \multicolumn{4}{|c|}{ Hamburgers (1+times per week) } & \multicolumn{4}{|c|}{ French fries (1+times per week) } & \multicolumn{4}{|c|}{ Fried chicken (1+times per week) } \\
\hline & $n$ & $\% *$ & OR $(95 \% \mathrm{Cl})$ & $P$-value & $n$ & $\%$ & OR $(95 \% \mathrm{Cl})$ & $P$-value & $n$ & $\%$ & OR $(95 \% \mathrm{Cl})$ & $P$-value \\
\hline \multicolumn{13}{|c|}{ Daily TV watching } \\
\hline$<1 \mathrm{~h}$ & 282 & 16.2 & 1.0 & & 282 & 48.7 & 1.0 & & 282 & 17.9 & 1.0 & \\
\hline 1 to $<2 h$ & 342 & 24.3 & $1.8(1.1-2.9)$ & & 342 & 60.9 & $1.7(1.1-2.7)$ & & 342 & 16.3 & $0.9(0.6-1.4)$ & \\
\hline$\geq 2 \mathrm{~h}$ & 402 & 27.3 & $1.8(1.2-2.9)$ & 0.018 & 402 & 69.9 & $2.4(1.4-4.0)$ & 0.003 & 402 & 18.9 & $0.9(0.6-1.5)$ & 0.91 \\
\hline
\end{tabular}

${ }^{*}$ Weighted percentages; unadjusted for effects of age, ethnicity, sex, and socio-economic status.

the USA has also shown that children from lower socio-economic families are more frequent viewers of $\mathrm{TV}^{23}$.

The current study suggests that TV use is an independent correlate of obesity among New Zealand's children and young adolescents. This is consistent with other nationally representative cross-sectional surveys ${ }^{9-11}$, longitudinal studies $^{12,13}$ and a randomised controlled trial ${ }^{14}$, which have identified TV use as an important modifiable factor contributing to obesity. It is interesting that TV use was not associated with overweight, but this may be due to the loss of information in categorising BMI. It may also be that while a number of factors can contribute to excess weight gain, TV and advertising have greater influence on food choices and consumption patterns than other factors. Experimental studies have shown that children exposed to food advertising will consistently choose the advertised product at a higher rate than children not exposed ${ }^{24}$. Likewise, exposing children to advertising results in more attempts to influence the products that their parents buy ${ }^{24}$.
In general, longer duration of TV watching (and, thus, more frequent exposure to food advertising) was associated with high frequency of consumption of the most commonly advertised foods on TV, particularly for children. New Zealand children and adolescents who watch the most TV are more likely to be the most frequent consumers of sugary drinks, some sweets and snacks, and some fast foods, and less likely to be high consumers of fruit, than students watching less than one hour of TV a day. Our findings are consistent with previous studies demonstrating that TV viewing is associated with less desirable dietary behaviours, including increased consumption of high-energy snack foods ${ }^{25}$, pizza and soft drinks ${ }^{23,26}$ and fewer fruits and vegetables $^{23,26-28}$.

The current study has several strengths that add value to previous studies on the topic. First, the study sample comprised a large, randomly selected body of New Zealand children and adolescents aged 5 to 14 years. This 
is the first time that detailed information about the nutritional status and behaviours of New Zealand's children and adolescents has ever been available. Second, the methodology included an FFQ designed specifically for foods most commonly eaten by New Zealand children and adolescents. Third, the current study's a priori hypothesis was based on previous scientific evidence; food items were selected for analysis using data previously collected in two content analyses of New Zealand TV advertisements airing during the times that children and young adolescents commonly watch TV. This is important as New Zealanders are a contained population with relative homogeneity in their media exposure.

However, the current study has a few limitations that are important to mention. First, the study design is cross-sectional; conclusions about the directionality of the findings cannot be determined. For example, it may be that obese adolescents watch more TV because being obese prohibits them from participating in other activities. We know from two longitudinal studies, however, that TV watching precedes obesity and that TV use during childhood is an independent predictor of weight gain $^{12,13}$. Second, although the FFQ used in the current study has been designed and satisfactorily tested for New Zealand children and adolescents, FFQs are limited in their ability to assess dietary intakes ${ }^{29}$. Third, the measure used for TV viewing in the current study did not discriminate between commercial TV, non-commercial TV and videos. This is important as the frequency of advertising across these media may not be consistent. That said, commercial TV is the most pervasive media used by children and adolescents $^{30}$. Finally, our findings may be limited by other factors that may act as missing predictors (such as family and school environments) in the associations between TV watching and weight status and dietary behaviours.

In New Zealand, nearly one-third of children between the ages of 5 and 14 years are overweight or obese ${ }^{16}$. The current study provides valuable information for exploring one of the independent correlates of obesity: TV use. Findings from the current study suggest that the relationship between TV use and obesity may be mediated by exposure to food advertising. While it is difficult to argue that advertising has direct control over children's behaviour, it may be that the ubiquitous nature of food advertising shapes ideas about what types of foods are consistent with a 'normal' diet ${ }^{31}$. Likewise, reminding children to consume a product and providing incentives to do so is also likely to increase consumption ${ }^{31}$. Members of the food industry have publicly claimed that TV advertising is effective only in creating brand loyalty, not in increasing category growth ${ }^{32}$. Our findings demonstrate that children and adolescents who watch the most TV also more frequently consume foods commonly advertised: sugary drinks, sweets and snacks, and fast foods. Findings from the current study have implications for improving child and adolescent nutrition, particularly in New Zealand.
In New Zealand, advertising to children (under age 14) is self-regulated in accordance with the Codes for Advertising to Children established by the Advertising Standards Authority ${ }^{33}$. The effectiveness of self-regulation compared with stricter legislation is questionable ${ }^{34}$. Studies examining the impact of advertising on children's diets through interventions and international comparisons of legislation would provide more definitive evidence of the role of advertising in child and adolescent obesity.

\section{Acknowledgements}

The CNSO2 was funded by the New Zealand Ministry of Health. The Principal Investigators of $\mathrm{CNSO2}$ were Dr Robert Scragg and Mr David Schaaf (University of Auckland), Mr Eljon Fitzgerald (Massey University), and Mrs Winsome Parnell and Dr Noela Wilson (University of Otago).

\section{References}

1 Hammond K, Wyllie A, Casswell S. The extent and nature of televised food advertising to New Zealand children and adolescents. Australian and New Zealand Journal of Public Health 1999; 23(1): 49-55.

2 Wilson N, Quigley R, Mansoor O. Food ads on TV: a health hazard for children? Australian and New Zealand Journal of Public Health 1999; 23(6): 647-50.

3 Philippas NG, Lo CW. Childhood obesity: etiology, prevention, and treatment. Nutrition in Clinical Care 2005; 8(2): $77-88$.

4 AC Nielsen. Nielsen Media Research Advertising Information. Auckland: AC Nielsen, 2003.

5 Bauman A, McLean G, Hurdle D, Walker S, Boyd J, van Aalst I, et al. Evaluation of the national 'Push Play' campaign in New Zealand - creating population awareness of physical activity. New Zealand Medical Journal 2003; 116(1179): 535-46.

6 Neville L, Thomas M, Bauman A. Food advertising on Australian television: the extent of children's exposure. Health Promotion International 2005; 20(2): 105-12.

7 Lewis MK, Hill AJ. Food advertising on British children's television: a content analysis and experimental study with nine-year olds. International Journal of Obesity and Related Metabolic Disorders 1998; 22(3): 206-14.

8 Taras HL, Gage M. Advertised foods on children's television. Archives of Pediatrics \& Adolescent Medicine 1995; 149(6): 649-52.

9 Tremblay M, Willms J. Is the Canadian childhood obesity epidemic related to physical activity? International Journal of Obesity and Related Metabolic Disorders 2003; 27(9): $1100-5$

10 Crespo C, Smit E, Troiano R, Bartlett S, Macera C, Andersen R. Television watching, energy intake, and obesity in US children results from the third National Health and Nutrition Examination Survey, 1988-1994. Archives of Pediatrics \& Adolescent Medicine 2001; 155(3): 360-5.

11 Andersen R, Crespo C, Bartlett S, Cheskin L, Pratt M. Relationship of physical activity and television watching with body weight and level of fatness among children: results from the Third National Health and Nutrition Examination Survey. Journal of the American Medical Association 1998; 279(12): 938-42.

12 Proctor M, Moore L, Gao D, Cupples L, Bradlee M, Hood M, et al. Television viewing and change in body fat form 
preschool to early adolescence: The Framingham Children's Study. International Journal of Obesity and Related Metabolic Disorders 2003; 27(7): 827-33.

13 Hancox R, Milne B, Poulton R. Association between child and adolescent television viewing and adult health: a longitudinal birth cohort study. Lancet 2004; 364(9430): 257-62.

14 Robinson TN. Reducing children's television viewing to prevent obesity. Journal of the American Medical Association 1999; 282(16): 1561-7.

15 Linn SE. Food marketing to children in the context of a marketing maelstrom. Journal of Public Health Policy 2004; 25(3-4): 367-78.

16 Parnell W, Scragg R, Wilson N, Schaaf D, Fitzgerald E. NZ Food NZ Children: Key Results of the 2002 National Children's Nutrition Survey. Wellington: Ministry of Health, 2003.

17 Metcalf P, Scragg R, Sharpe S, Fitzgerald E, Schaaf D, Watts C. Short-term repeatability of a food frequency questionnaire in New Zealand children aged 1-14y. European Journal of Clinical Nutrition 2003; 57(11): 1498-503.

18 Cole T, Bellizzi M, Flegal K, Dietz W. Establishing a standard definition for child overweight and obesity worldwide: international survey. British Medical Journal 2000; 320(7244): 1240-3.

19 Kowalski K, Crocker P, Kowalski N. Convergent validity of the Physical Activity Questionnaire for Adolescents. Pediatric Exercise Science 1997; 9(4): 342-52.

20 Kowalski K, Crocker P, Faulkner R. Validation of the Physical Activity Questionnaire for Older Children. Pediatric Exercise Science 1997; 9(2): 174-86.

21 Crampton P, Salmond C, Kirkpatrick R, Scarborough R, Skelly C. Degrees of Deprivation in New Zealand. An Atlas of Socioeconomic Difference. Auckland: David Bateman Ltd, 2000

22 Howden-Chapman P, Tobias M, eds. Social Inequalities in Health: New Zealand 1999. Wellington: Ministry of Health, 2000

23 Utter J, Neumark-Sztainer D, Jeffery R, Story M. Couch potatoes or french fries: are sedentary behaviors associated with body mass index, physical activity, and dietary behaviors among adolescents? Journal of the American Dietetic Association 2003; 103(10): 1298-305.

24 Coon KA, Tucker KL. Television and children's consumption patterns. A review of the literature. Minerva Pediatrica 2002; 54(5): 423-36.

25 Phillips S, Bandini L, Naumova E, Cyr H, Colclough S, Dietz W, et al. Energy-dense snack food intake in adolescence: longitudinal relationship to weight and fatness. Obesity Research 2004; 12(3): 461-72.

26 Coon K, Goldberg J, Rogers B, Tucker K. Relationships between use of television during meals and children's food consumption patterns. Pediatrics 2001; 107(1): E7.

27 Lowry R, Wechsler H, Galuska D, Fulton J, Kann L. Television viewing and its associations with overweight, sedentary lifestyle, and insufficient consumption of fruits and vegetables among US high school students: differences by race, ethnicity, and gender. Journal of School Health 2002; 72(10): 413-21.

28 Boynton-Jarrett R, Thomas T, Peterson K, Wiecha J, Sobol A, Gortmaker S. Impact of television viewing patterns on fruit and vegetable consumption among adolescents. Pediatrics 2003; 112(6): 1321-6.

29 Gibson R. Principles of Nutritional Assessment. Oxford: Oxford University Press, 2005.

30 Rideout V, Roberts D, Foehr U. Generation M: Media in the Lives of 8-18 year-olds. Menlo Park, CA: Kaiser Family Foundation, 2005

31 Hoek J. Marketing communications and obesity: a view from the dark side. New Zealand Medical Journal 2005. 118(1220): 1608.

32 Food Advertising Unit. Advertising Association Executive Brief: Advertising to Children. London: Food Advertising Unit, 2003.

33 Advertising Standards Authority. Codes for Advertising to Children. Wellington: Advertising Standards Authority, 2001.

34 Story M, French S. Food advertising and marketing directed at children and adolescents in the US. International Journal of Behavioral Nutrition and Physical Activity 2004; 1(1): 3. 